\title{
Inequity in postpartum healthcare provision at home and its association with healthcare expenditure
}

Erasmus MC Sophia Children's Hospital

Authors: Jacqueline Lagendijk ${ }^{1}$, Eric A.P. Steegers ${ }^{1}$, Jasper V. Been ${ }^{1,2}$

Presenting author: j.been@erasmusmc.nl

${ }^{1}$ Department of Obstetrics and Gynaecology, Erasmus MC. ${ }^{2}$ Division of Neonatology, Erasmus MC - Sophia Children's Hospital, University Medical Centre Rotterdam, PO Box 2040, 3000 CA, Rotterdam, the Netherlands

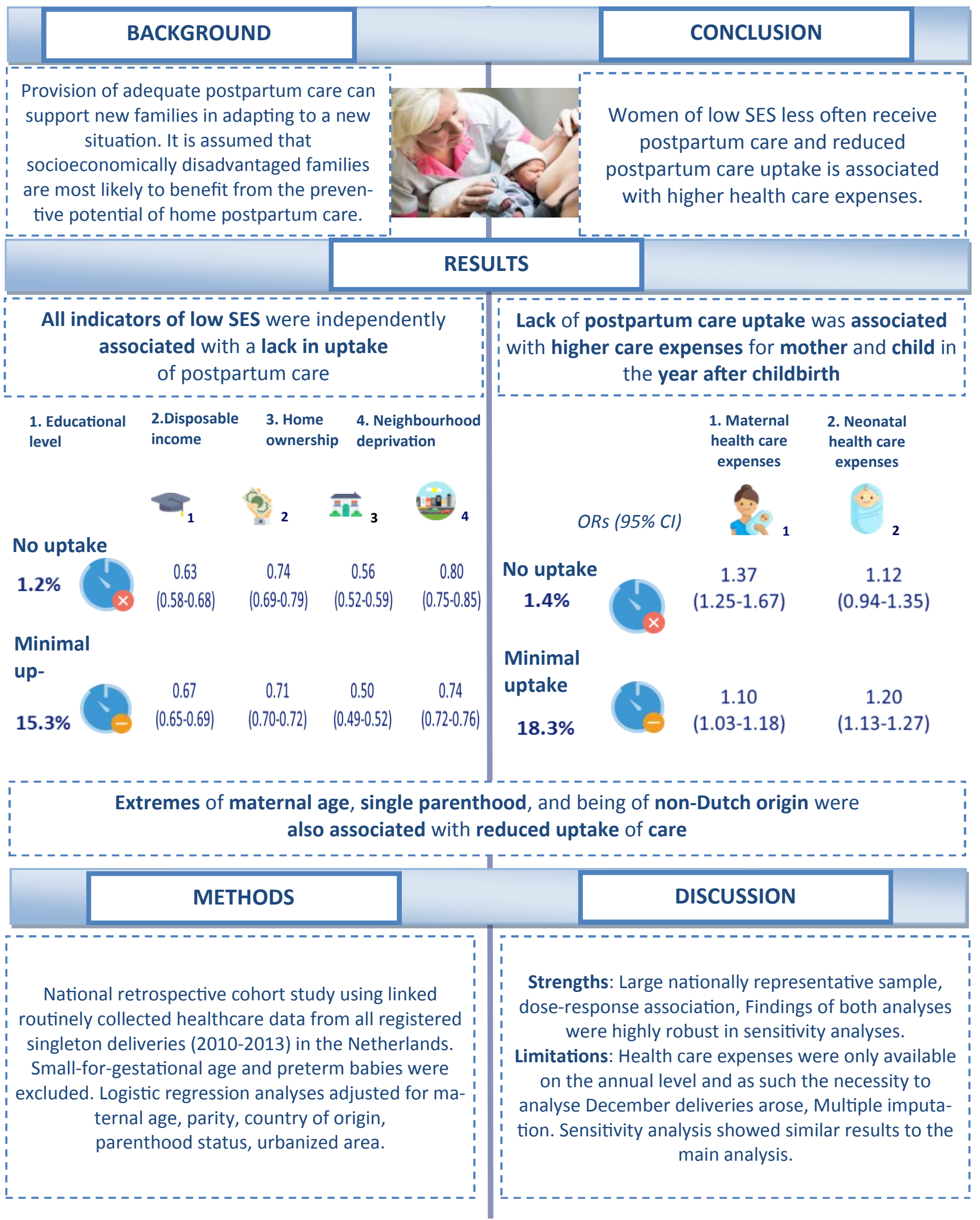

